\title{
UROLOGICAL INJURIES IN OBSTETRICS AND GYNAECOLOGY
}

Vandana Bisht ${ }^{1}$, Usha Rawat ${ }^{2}$, Kanchan Rani3 ${ }^{3}$ Priyanka Chauhan ${ }^{4}$

\section{HOW TO CITE THIS ARTICLE:}

Vandana Bisht, Usha Rawat, Kanchan Rani, Priyanka Chauhan. "Urological injuries in obstetrics and gynaecology". Journal of Evolution of Medical and Dental Sciences 2013; Vol. 2, Issue 45, November 11; Page: 8801-880 4

ABSTRACT: To review the frequency of iatrogenic urological injury during obstetric and gynaecological operations carried out between January 2009 to January 2013 at Government Medical College, Haldwani. Each case was reviewed for predisposing factors, location, type of injury, time of injury, method of recognition and management. 12 injuries were documented in 1063 gynaecological procedures and 3079 obstetric procedures. All were bladder injuries and occurred while separating the blad der. Pelvic adhesions was the most common factor.

INTRODUCTION: The reproductive and urinary tracts in women are closely related anatomically and embryologically. Injury to the urinary tract involves injury to the ureters, bladder and urethra (1). The overall rate of urinary tract injury associated with pelvic surgery in women is associated with pelvic surgery in women is approximately $1 \%$ (2). Bladder injury is more common than ureteral injury (3). However, the exact incidence of these injuries is difficult to ascertain.

Urological injuries in gynaecological surgeries result due to difficult surgery, active infection, endometriosis, enlarged uterus, previous pelvic surgery, pelvic adhesions, ovarian neoplasms, distorted pelvic anatomy, cervical fibroids, broad ligament fibroids, tubo-ovarian mass, advanced malignancies, previous surgery. Such a history should caution on risk of injury and suggest for further preoperative evaluation $(4,5)$. Diagnosis of urological injuries can be made intraoperatively or postoperatively. Majority of bladder injuries are diagnosed intraoperatively. Intraoperative identification of urological injuries enables prompt repair and is associated with decreased morbidity.

MATERIAL AND METHODS: This study was conducted in the department of obstetrics and gynaecology, Government medical college, Haldwani. This study included 4142 patients over a period of four years from Jan 2009 to Jan 2013 who underwent Caesarean section, TAH, VH and NDVH. The urological injury which occurred during surgery, its site, time of occurrence, predisposing risk factors, its management and prognosis were analyzed.

OBSERVATION: During this period, 3079 C.S, 480 TAH, 343 VH, 240 NDVH were conducted. Total 12 case of bladder injury occurred during surgery. 5 out of NDVH, 2 out of $343 \mathrm{VH}, 2$ out of $480 \mathrm{TAH}$ and 3 out of 3079 CS had bladder injuries (Table 1).

\begin{tabular}{|c|c|c|}
\hline Name of surgery & Total No. of surgeries & No. of bladder injury \\
\hline NDVH & 240 & 5 \\
\hline VH & 343 & 2 \\
\hline TAH & 480 & 2 \\
\hline CS & 3079 & 3 \\
\hline
\end{tabular}

Table 1: Distribution of bladder injuries in different obstetric and gynaecologic surgeries 
All bladder injuries occurred while separating the bladder. All the injuries were diagnosed there only by direct inspection of the injury.

All the patients who underwent hysterectomy were $>40$ years and the most common indication was Dysfunctional Uterine Bleeding followed by Fibroid uterus (Table 2, 3)

\begin{tabular}{|c|c|}
\hline Age of the patient (years) & No. of cases \\
\hline $20-30$ & 3 \\
\hline $40-50$ & 8 \\
\hline $50-60$ & 1 \\
\hline $\begin{array}{c}\text { Table 2: Distribution of bladder injuries cases } \\
\text { according to the age of the patients }\end{array}$ \\
\hline
\end{tabular}

\begin{tabular}{|c|c|c|}
\hline Diagnosis & Surgery & No. of cases \\
\hline DUB & NDVH & 4 \\
\hline Fibroid & TAH & 2 \\
\hline Adenomyosis & NDVH & 1 \\
\hline U - V prolapsed & VH & 2 \\
\hline Previous C.S. & CS & 2 \\
\hline Obstructed labour & CS & 1 \\
\hline
\end{tabular}

Table 3: Distribution of bladder injuries cases according to the diagnosis and surgery done

Among 5 cases of NDVH in which bladder injury occurred, all were repaired vaginally followed by hysterectomy by the same route. In one case, hysterectomy was completed by abdominal route as bladder couldn't be separated. All the bladder injuries during TAH and CS were repaired by abdominal route (Table 4 ).

\begin{tabular}{|c|c|c|c|}
\hline Surgery & Bladder injury & Repair & Post operative complication \\
\hline NDVH & 4 & Vaginal & Nil \\
\hline 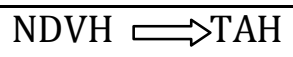 & 1 & Vaginal & Nil \\
\hline TAH & 2 & Abdominal & Nil \\
\hline $\mathrm{VH}$ & 2 & Vaginal & Nil \\
\hline $\mathrm{CS}$ & 3 & Abdominal & Leakage of urine in 1 \\
\hline
\end{tabular}

Out of 3079 CS, 3 patients had bladder injuries which were repaired immediately. Out of these 3 females, one developed leakage of urine on $8^{\text {th }}$ postoperative day. This female had 2 previous Caesarean section and was brought to our hospital with 35 weeks pregnancy in labour. She was taken for CS for scar tenderness and on opening the abdomen, dense adhesions were present between the anterior abdominal wall, uterus and bladder. While separating the bladder, injury to the bladder occurred. After closing the uter us, bladder was repaired in 2 layers. On the $8^{\text {th }}$ post operative day, she developed leakage of urine vaginally. 
DISCUSSION: Iatrogenic urological injuries are still common in our environment. In order to reduce the risk of injury, adequate pre operative preparation is recommended and meticulous surgical technique based on proper understanding of the anatomy of the urogenital system should be practised by the surgeon. Urinary tract injuries are common complications of pelvic surgeries. Although a few instances have been noted, they remain a source of great concern to the surgeons due to their associated morbidities. Bladder injuries are more common than ureteric injuries. In our study, out of 4142 gynaecologic and obstetric surgeries, 12 cases $(0.28 \%)$ of bladder injury occurred. The incidence of ureteral and urethral injuries were nil. 5 cases of bladder injury occurred while doing NDVH. The incidence was $2.08 \%$.

The incidence of bladder injury was significantly higher in NDVH compared with TAH and VH. Bladder injuries detected during NDVH and VH could be managed through vaginal route. All the repairs healed successfully.

All the bladder injuries were detected during surgeries only. These were diagnosed by the appearance of fluid which is the first indication of trauma to bladder. Instillation of normal saline with methylene blue confirmed the injury. The bladder defects were repaired in 2 layers with absorbable stitches and integrity was checked by distending the bladder with dilute methylene blue. The foley's catheter was kept in all cases for 14-21 days postoperatively. We also noticed that all bladder injuries were cut with laceration type and was probably because of the gauze dissection while pushing the bladder away.

The bladder is the most commonly injured organ during obstetric and gynaecological interventions. Prompt recognition and repair of injuries should be the main goal. Using aqua dissection helps not only in getting a clear cleavage but also preventing bladder injury. Bladder damage is not generally catastrophic if it is recognized and treated promptly.

\section{REFERENCES:}

1. Purandare CN. Urological injuries in gynaecology. J Obstet Gynecol India 57 (3): 2007; 203 204.

2. Gilmour DT, Das S, Flower dew G. Rates of urinary tract injury from gynaecology surgery and the role of intraoperative cystoscopy. Obstet Gynecol 2006; 107:1366.

3. Bai SW, Hich EH, Jung da J, et al. Urinary tract injuries during pelvic surgery: incidence rates and predisposing factors. Int Urogynecol J Pelvic floor Dysfunct 2006; 17:360.

4. Reynaldo G, Cephallos L, Coburn M, J N Corriere, M C Dixon, Lobels B, et al, Consensus statement on bladder injuries. BJU International 2004; 94:27-32.

5. Mendez L E, Iatrogenic injuries in gynecologic cancer surgery. Surg clin North Am 2001; 81:897-923. 


\section{AUTHORS:}

1. Vandan Bisht

2. Usha Rawat

3. Kanchan Rani

4. Priyanka Chauhan

\section{PARTICULARS OF CONTRIBUTORS:}

1. Associate Professor, Departm ent of Obstetrics and Gynaecology, Government Medical College, Haldwani, Uttarakhand.

2. Professor, Department of Obstetrics and Gynaecology, Government Medical College, Haldwani, Uttarakhand.

3. Assistant Professor, Department of Obstetrics and Gynaecology, Government Medical College, Haldwani, Uttarakhand.
4. Resident, Department of Obstetrics and Gynaecology, Government Medical College, Haldwani, Uttarakhand.

\section{NAME ADDRESS EMAIL ID OF THE CORRESPONDING AUTHOR:}

Dr. Vandana Bisht,

Department of Obstetrics and Gynaecology, Government Medical College,

Haldwani, Uttarakhand.

Email - priyanka.nitingarg@gmail.com

Date of Submission: 26/10/2013.

Date of Peer Review: 27/10/2013.

Date of Acceptance: 30/10/2013.

Date of Publishing: 06/11/2013 